the lateral side of the aorta. Furthermore, the mass was draped lobulated around the lumen of the aorta. These findings were suggestive of a tumor. The diagnosis of a tumor was strengthened by demonstration of vascularity in the mass by Doppler ultrasonography and enhancement of the mass on MRI. The malignant nature of the tumor was highly suspected as a result of the high uptake on PET scan; to our knowledge, a preoperative PET scan of an aortic sarcoma has never been described. Owing to the low incidence of aortic sarcoma, the premortem diagnosis and imaging of aortic sarcoma is highly unusual.

Although aortic sarcoma remains an exceptional disease, its presence should be considered in a case of atypical presentation of a symptomatic aortic aneurysm. Furthermore, a high degree of uncertainty is needed when interpreting imaging techniques in these patients. ${ }^{2}$

\section{References}

1. Steinberg JB, Johnson ER, Benda JA, Lanza LA. Primary leiomyosarcoma of the thoracic aorta presenting as a contained rupture. Ann Thorac Surg. 1993;56:1387-9.

2. Muehlstedt S, Mallery S, Joyce L, Van Camp J. Myxoid leiomyosarcoma of the descending thoracic aorta. $J$ Thorac Cardiovasc Surg. 2001;121:590-2.

\title{
Reversing the Ross operation: A new reoperation option for autograft failure
}

\author{
Michael Flynn, FRCSI(C/Th), ${ }^{a}$ Sherard G. Little, MD, ${ }^{a}$ Eugene H. Blackstone, MD, a,b \\ and Gösta B. Pettersson, MD, PhD, ${ }^{\text {a }}$ Cleveland, Ohio
}

I

$\mathrm{n}$ the late 1980s, Stelzer and Elkins ${ }^{1}$ popularized the Ross operation by simplifying it, achieving good and consistent results after autograft implantation as a full freestanding root. However, in the late 1990s, David and colleagues ${ }^{2}$ called attention to progressive dilatation of the autograft root that caused regurgitation and eventual failure. Prevalence of reoperation up to $25 \%$ at 10 years has been observed even in larger series. ${ }^{3}$

For patients with autograft dilatation and aortic regurgitation, surgical options include valve-sparing David reimplantation, composite graft (Bentall), or allograft root replacement. Most of these patients do not have an autograft-sparing procedure; rather, they have the autograft replaced and are left with an allograft remaining in the pulmonary position that is subject to future deterioration.

In this communication, we describe clinical and operative details of 3 patients from an initial experience of reversing the Ross operation by autograft excision and reuse in its native pulmonary position.

From the Departments of Thoracic and Cardiovascular Surgery a and Quantitative Health Sciences, ${ }^{\text {b }}$ Cleveland Clinic, Cleveland, Ohio.

Received for publication Jan 22, 2007; accepted for publication Jan 31, 2007.

Address for reprints: Gösta B. Pettersson, MD, PhD, Cleveland Clinic, Department of Thoracic and Cardiovascular Surgery, 9500 Euclid Ave/ Desk F24, Cleveland, Ohio 44195 (E-mail: petterg@ccf.org).

J Thorac Cardiovasc Surg 2007;133:1645-7

$0022-5223 / \$ 32.00$

Copyright $\odot 2007$ by The American Association for Thoracic Surgery doi:10.1016/j.jtcvs.2007.01.056

\section{Clinical Summaries}

Clinical and operative details of 3 male patients, all of whom originally had bicuspid aortic valve disease, are described in Table 1. Patient 3 had undergone pulmonary allograft dilatation and stenting 3 years after the Ross procedure.

All patients had transesophageal echocardiography (TEE). After resternotomy, the right side of the heart and aorta were mobilized and cardiopulmonary bypass instituted. Induction with antegrade and retrograde cold blood cardioplegia, followed by retrograde cardioplegia delivered at 15 -minute intervals and warm terminal cardioplegia, provided myocardial protection. Two patients required brief hypothermic circulatory arrest and retrograde cerebral perfusion for hemiarch replacement.

Presence of good autograft cusps was confirmed. Coronary buttons were excised, maintaining a rim of healthy tissue around the ostia. The autograft was carefully dissected out and excised from the left ventricular outflow tract (Figure 1, A). In all 3 cases, autografts had an approximately $1-\mathrm{cm}$-wide fibrous margin between the cusps and left ventricle, allowing excision with a 3- to 4-mm rim of tissue for reimplantation, while not compromising the left ventricular outflow tract. The previously scalloped autograft was refashioned with autologous pericardium (Figure 1,B).

The pulmonary allograft was radically excised, leaving no allograft, inflammatory, or scar tissue behind.

The proximal anastomosis of a composite aortic root replacement or allograft root was completed in standard fashion and the coronary buttons anastomosed anatomically with continuous 5-0 polypropylene suture. The refashioned pulmonary autograft was reimplanted into the right ventricular outflow tract in anatomic orientation with continuous 4-0 monofilament sutures for both distal and proximal anastomoses. Finally, the 
TABLE 1. Patient clinical, operative, and outcome details

\begin{tabular}{|c|c|c|c|}
\hline \multirow[b]{2}{*}{ Details } & \multicolumn{3}{|c|}{ Patient No. } \\
\hline & 1 & 2 & 3 \\
\hline \multicolumn{4}{|l|}{ Clinical } \\
\hline Age (y) & 37 & 28 & 67 \\
\hline Time since Ross procedure (mo) & 138 & 77 & 73 \\
\hline Neo-aorta/valve pathology & Aneurysm, 3+ AR & Aneurysm, 1+ AR & Dilatation, 4+ AR \\
\hline Allograft/RVOT pathology & Moderate stenosis & Mild stenosis, $1+$ PR & Severe stenosis \\
\hline Original autograft technique & Root replacement & Root replacement & Root replacement \\
\hline \multicolumn{4}{|l|}{ Operative } \\
\hline Aortic root implant & 27-mm composite, mechanical & 31-mm composite, mechanical & Allograft, 28 mm \\
\hline $\begin{array}{l}\text { Hypothermic circulatory arrest time } \\
\text { (min) }\end{array}$ & 16 & 18 & 0 \\
\hline Myocardial ischemic time (min) & 153 & 137 & 162 \\
\hline CPB time (min) & 186 & 160 & 178 \\
\hline \multicolumn{4}{|l|}{ Outcome } \\
\hline Postoperative PR & $1+$ & 0 & 0 \\
\hline Hospital stay (d) & 7 & 8 & 6 \\
\hline
\end{tabular}

$A R$, Aortic regurgitation; $C P B$, cardiopulmonary bypass; $P R$, pulmonary regurgitation; $R V O T$, right ventricular outflow tract.

aortic root implant was anastomosed to the distal ascending aorta or distal aortic graft with continuous 4-0 monofilament suture (Figure 1,C). After separation from bypass, TEE confirmed good valve function.

All patients had transthoracic echocardiography and computed tomography before hospital discharge.

\section{Discussion}

In patients who have had the Ross procedure, the method described in the present study addresses (1) pulmonary autograft dilatation with secondary aortic regurgitation and (2) possible long-term implications of an allograft in the pulmonary position. This technique achieved excellent clinical and echocardiographic results. Even when the autograft was dilated and its valve regurgitant, if leaflet structure was good, the downsized reconstructed autograft appeared suitable for reuse. Function of the pulmonary valve was excellent after the procedure.
This is a long and technically demanding operation, but it was well tolerated by these patients, as evidenced by their smooth postoperative courses and short hospital stays.

For autograft dysfunction associated with dilatation, aortic root reimplantation according to David has been described. ${ }^{4}$ Although conceptually attractive, the amount of tissue surrounding the autograft, combined with an asymmetric appearance of autograft cusps at the time of the attempted David procedure, resulted in abandoning it on two previous occasions in our hands. However, technical feasibility of the David procedure in this setting has been demonstrated, and it remains one of the options discussed with the patient. One of the patients in this series declined this option. The ideal patient for the David procedure would have moderate autograft dilatation, central regurgitation, symmetric autograft cusps, and a perfect pulmonary allograft. Data demonstrating longevity and durability of the David reimplantation procedure after the Ross operation
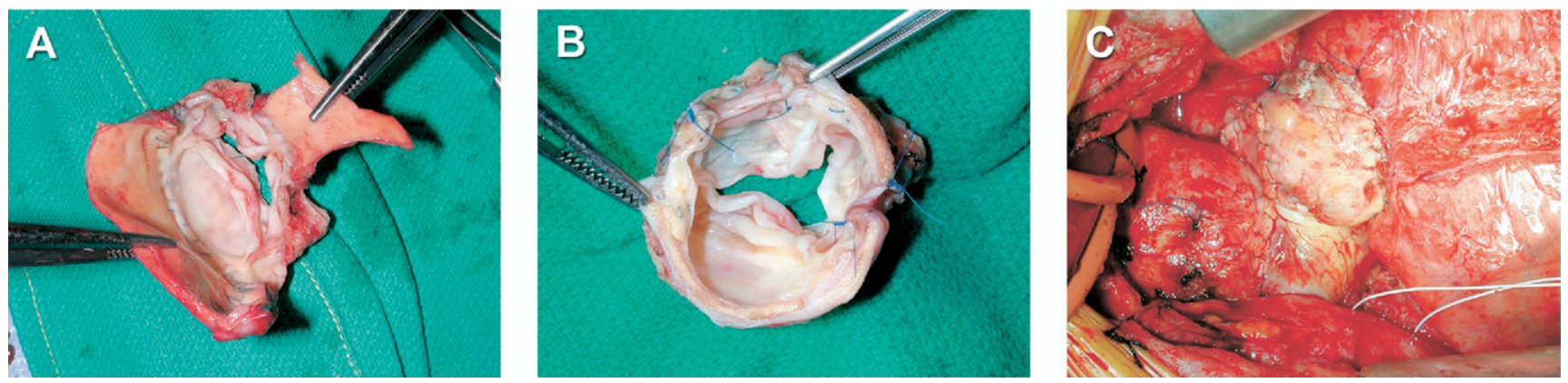

Figure 1. Pulmonary autograft reimplantation into the native position after the Ross procedure. A, Explanted autograft. B, Scalloped autograft refashioned with autologous pericardium. C, Reimplanted autograft before separation from cardiopulmonary bypass. 
may never be more than anecdotal. The allograft aortic root replacement option for a failed Ross procedure without reuse of the autograft gives the patient two allografts with potential for degeneration and need for subsequent technically demanding reoperations.

Our own experience with reoperation after the Ross procedure now exceeds 30 patients. Two thirds of these reoperations have related primarily to autograft failure; in retrospect, many of these patients could have benefited from the reversal described. Patients have also expressed psychologic relief. At this early stage, we are hopeful that the reversal procedure is a good, durable option for many patients with a failed Ross procedure.

\section{References}

1. Stelzer P, Elkins RC. Pulmonary autograft: an American experience. J Card Surg. 1987;2:429-33.

2. David TE, Omran A, Ivanov J, Armstrong S, de Sa MP, Sonnenberg B, et al. Dilation of the pulmonary autograft after the Ross procedure. J Thorac Cardiovasc Surg. 2000;119:210-20.

3. Kouchoukos NT, Masetti P, Nickerson NJ, Castner CF, Shannon WD, Davila-Roman VG. The Ross procedure: long-term clinical and echocardiographic follow-up. Ann Thorac Surg. 2004;78:773-81; discussion 773-81.

4. Leyh RG, Kofidis T, Fischer S, Kallenbach K, Harringer W, Haverich A. Aortic root reimplantation for successful repair of an insufficient pulmonary autograft valve after the Ross procedure. $J$ Thorac Cardiovasc Surg. 2002;124:1048-9.

\title{
Long abdominal aortic stenosis: A rare presentation of Takayasu arteritis treated with percutaneous stent implantation
}

\author{
Pasquale Perrone-Filardi, MD, Pierluigi Costanzo, BS, Paolo Cesarano, MD, Antonio Marzano, MD, \\ Giovanni Esposito, MD, Gabriele Iannelli, MD, and Massimo Chiariello, MD, Naples, Italy
}

$\mathrm{W}$ e describe the case of a patient with a long abdominal aortic stenosis. This condition can have different causes. On the basis of the American College of Rheumatology criteria and Sharma's diagnostic criteria, the cause in this patient was a rare presentation of Takayasu arteritis. Generally, this vasculitis affects the epiaortic arteries, causing diminished or absent pulses in the upper limbs; in this case, the arteritis affected the abdominal aorta, causing claudication of the lower limbs.

\section{Clinical Summary}

A 46-year-old woman was admitted to our department for claudication of the lower limbs. The claudication started 6 years before at the right limb and then progressed to the left limb, reaching a maximal walking distance of less than $100 \mathrm{~m}$ at the time of hospitalization. An echo-Doppler of the lower limbs demonstrated the absence of obstructive lesions. We performed an abdominal angio-computed tomographic scan with volumetric reconstruction that showed a long stenosis of the infrarenal aorta with a maximum diameter of less than $1.5 \mathrm{~cm}$ (Figure 1,

From the Department of Internal Medicine, Cardiovascular and Immunological Sciences, Federico II University, Naples, Italy.

Received for publication Jan 22, 2007; accepted for publication Jan 31, 2007.

Address for reprints: Pasquale Perrone Filardi, Via S. Pansini 5, Naples, 80131 Italy (E-mail: fpperron@unina.it).

J Thorac Cardiovasc Surg 2007;133:1647-8

$0022-5223 / \$ 32.00$

Copyright $\odot 2007$ by The American Association for Thoracic Surgery doi:10.1016/j.jtcvs.2007.01.063
$A, B)$. An abdominal echo-Doppler showed a long fibrotic plaque causing an obstruction of $40 \%$ of the lumen, with significant acceleration of speed without lesions at the renal and iliac arteries. Echo-Doppler of the carotid and subclavian arteries was normal. An angiographic study of the coronary and aortic tree showed multiple coronary stenosis that was hemodynamically not significant but atypical for the age and normal lipidemic profile of the patient $(50 \%$ stenosis of proximal left descending anterior artery, $40 \%$ stenosis of medium left descending anterior artery, and 50\% stenosis of medium circumflex artery). In the infrarenal aorta the angiographic study showed a hemodynamically significant long narrowing lesion (Figure 2, A). The assessment of inflammatory indexes revealed a high erythrocyte sedimentation rate. Finally, a percutaneous transluminal angioplasty with successful stent implantation was performed at the level of the infrarenal aorta (Figure 2,B) with immediate cessation of symptoms.

\section{Discussion}

Congenital coarctation of the thoracic aorta at the ligamentum arteriosum or aortic arch is well recognized. A much less common variety $(0.5 \%-2.0 \%)$ of aortic coarctation is located in the distal thoracic aorta, abdominal aorta, or both, and is usually called "middle aortic syndrome." 1 This definition includes different causes: congenital, Takayasu arteritis, neurofibromatosis, retroperitoneal fibrosis, and mucopolysaccharidosis. In our case, we excluded the last 3 diseases and considered a congenital coarctation or Takayasu arteritis. Some authors distinguish the abdominal localization of Takayasu arteritis from the congenital coarctation on the basis that the aortic stenosis in Takayasu arteritis affects a long tract of the infrarenal aorta without involvement of the renal arteries, whereas the aortic 